\title{
BORİK ASİT KATKILI ELEKTRO PORSELEN ÜRETİMİ VE ÖZELLİKLERİNİN İNCELENMESİ
}

\author{
Aziz Emre BÍLGíN ${ }^{1}$, Hakan GÖKMEŞE ${ }^{2}$, Bülent BOSTAN ${ }^{3}$ \\ ${ }^{1,3}$ Gazi Üniversitesi, Metalurji ve Malzeme Mühendisliği Bölümü, 06500, Ankara \\ ${ }^{2}$ Konya Necmettin Erbakan Üniversitesi, Seydişehir Ahmet Cengiz Mühendislik Fakültesi, Metalurji ve \\ Malzeme Mühendisliği Bölümü, 42360, Seydişehir, Konya \\ azizemre@hotmail.com, hgokmese@konva.edu.tr, $\underline{\text { bostan@gazi.edu.tr }}$
}

(Geliş/Received: 27.08.2014; Kabul/Accepted: 27.08.2015)

ÖZET

Sanayinin gelişmesi elektrik enerjisine ihtiyacı artırarak, izolatörlerin dış etkenlere ve artan şebeke voltajına karşı teknik özelliklerinin, mekanik dayanımının arttırılmasını ve ucuz yollu izolatör üretiminin gerekliliğini ortaya koymuştur. $\mathrm{Bu}$ amaçla, elektro-porselen masse çamuruna, \% 0,1, \% 0,3 ve \% $1 \mathrm{H}_{3} \mathrm{BO}_{3}$ katkılı hazırlanan numuneler, vakum preste şekillendirilerek kurutulduktan sonra, $1255^{\circ} \mathrm{C}$ sıcaklıkta, 2 saatte ve hava atmosferinde sinterlenmiştir. Numunelere tane boyut dağılımı, kuru küçülme, fuksin ve üç nokta eğme testleri uygulanmıştır. Mikroyapı karakterizasyonları bakımından XRD, SEM ve EDS analizleri yapılmıştır. \% 0,3'e kadar borik asit katkılı numunede tane boyut dağılımında azalma, \% 1 katkılı numunede kuru küçülme miktarında azalmanın en fazla ve genel olarak \% 0,3 borik asit katkılı numunenin işletme değerlerine daha yakın sonuçlar verdiği tespit edilmiştir. Dolayısıyla borik asit, elektro porselen bünyesine katkı maddesi olarak belirli oranda katılabildiğinde alternatif bir hammadde kaynağı olabileceği gözlemlenmiştir.

Anahtar Kelimeler: Elektro porselen, borik asit, sinterleme

\section{PRODUCTION OF ELECTRO PORCELAIN REINFORCED WITH BORIC ACID AND INVESTIGATION OF ITS PROPERTIES}

\begin{abstract}
The need of electrical energy is raised by the development of industry and that required to transportation of energy to the more distant points. All these developments reveal the need of cheaper insulator production and the need of enhancement of insulators' technical specifications and mechanical resistance against the increasing mains voltage and external factors. In the study, three different prescriptions, contain $0.1 \%, 0.3 \%$ and $1 \%$ $\mathrm{H}_{3} \mathrm{BO}_{3}$ additive, were prepared. Then, prepared samples were shaped on vacuum presses in the laboratory. After samples were dried, they were sintered at $1255^{\circ} \mathrm{C}$ for 2 hours in air. Particle size distribution, dry refinement, fuchsine and bending three point tests were applied to the samples. Characterizations of microstructure were performed by XRD, SEM and EDS analyses. At the end of the experimental studies, it was seen that depending on additive percentage, the reduction of particle size distribution is up to $0.3 \%$ and particle size is increasing with an increase in additive ratio. The maximum dry reduction amount was seen on the sample that contains $1 \%$ boric acid. In general, it was determined that the sample, which contains $0.3 \%$ boric acid, gives closer results to operation conditions. Therefore, it was observed that the boric acid could be an alternative raw material source, if it is incorporate into electro-ceramic at a certain ratio.
\end{abstract}

Keywords: Electro porcelain, boric acid, sintering

\section{GÍRIŞ (INTRODUCTION)}

Seramik, su ile yoğrulduğu zaman istenilen şekli alabilen, pişirildiğinde mukavemet ve su geçirimsizlik özelliği kazanan, ana maddesi ince taneli kil olan, birbirine kimyasal bağlar ile bağlanmış metaller ve alaşımları dışında kalan inorganik kökenli maddelerden üretilen malzemelerdir [1]. Seramik üretimi, uygun kalitede hammadde hazırlanmasından ürünün elde edildiği en son aşamaya kadar güç ve karmaşı bir süreçtir [2]. Porselen izolatörler; kaolin, kuvars ve feldspatın karışımından elde edilir [3]. 
İzolatörlerin iletken tel taşınımını sağlaması ve elektrik yalıtım görevini tam olarak yerine getirebilmesi gerekmektedir. Yüksek gerilim kablolarının zor şartlar altında (kuvvet, rüzgâr, buz, yüklü ve şiddetli sıcaklık farkına tabi bölgeler) garanti altına alınabilmesi için izolatörlerin uygun montaj ve mekanik boyutlarının doğru ölçümlendirilmesi gerekmektedir [4]. Günümüzde malzeme özelliklerinin mikro, makro ve dış etkenler açısından daha da iyileştirilmesi için katkı ilaveleri denenmektedir. Elektro porselen bünyelerde borik asidin alternatif bir ergitici olarak düşük oranlarda kullanım potansiyeli olduğu ortaya konulmuştur [5]. Borik asidin duvar karosu reçetelerinde düşük oranlarda nihai ürün performansını olumsuz yönde etkilemeden kullanılabileceği ortaya konulmuştur [6]. Tuğlaya katılan bor oksit ve borik asit katkısı \% 1 oranında yakın sonuçlar vermiş, katkı oranın biraz daha düşürülmesinin faydalı olabileceği önerilmiştir [7]. Borik asit ve boraks fren balatası komponentine katıldığında asbestin özelliklerini karşılayan alternatif bir malzeme olabileceği ifade edilmiştir [8].

$\mathrm{Bu}$ çalışmada, elektro porselen çamuruna borik asit katkısının etkisi genel olarak incelenmiş, elde edilen bünyenin dayanım ve mikro yapısal özelliklerinin borik asit ilavesi ile geliştirilmesi amaçlanmıştır.

\section{MATERYAL VE METOT (MATERIAL AND METHOD)}

Deneysel çalışmalarda standart işletme massesine (Kfeldspat+kuvars \%59, Kaolen \%16, Kil \%25) borik asit ilave edilerek üç farklı reçete hazırlanmıştır (Tablo 1). Hazırlanan masseye Tablo 1' de belirtilen reçetedeki oranlarda borik asit ilave edilerek, homojen bir karışım elde etmek için 4 saat karıştırma işlemine tabi tutulmuştur.

Tablo 1. Deneylerde kullanılan reçeteler (Recipes used in the experiments)

\begin{tabular}{|l|c|}
\hline Kullanılan Malzeme & Masse (\%) \\
\hline Masse + \% 0,1 Borik Asit & 99,9 \\
\hline Masse + \% 0,3 Borik Asit & 99,7 \\
\hline Masse + \% 1 Borik Asit & 99 \\
\hline
\end{tabular}

Vakum presten geçirilen massenin daha homojen olması için 24 saat bekletilmiştir. Uygun bir nem düzeyine ulaşan masse, tekrar vakum presten geçirilerek belirli bir uzunlukta şekillendirilmiştir. Kuru küçülme testi için eni $5 \mathrm{~cm}$, boyu ise $10 \mathrm{~cm}$ olacak şekilde numuneler hazırlanmıştır. Şekillendirilen numuneler mukavemet kazanması ve kuru küçülme tespiti için bir gün etüvde bekletilmiştir. Kuru küçülme tespiti için ayrılan numune, etüvde $15 \mathrm{dk}$ aralıklarla ölçülerek kuru küçülme tespiti yapılmıştır. Kurutulmuş numuneler sırlandıktan sonra isıl işlem firınında $1255{ }^{\circ} \mathrm{C}$ sıcaklıkta pişirilmiştir. Daha sonra numunelerin üç nokta eğme mukavemeti (kırılma mukavemeti), Denklem 1' e göre (L silindir boyu, D silindir çap1) otomatik olarak hesaplayan Mastersizer 2000 tip cihaz ile tespit edilmiştir.

Kırılma Mukavemeti $(\sigma)=8 \mathrm{FL} / \Pi^{3}$

Malzemelerde gözeneklerinin veya mikro çatlaklarının olup olmadığının tespiti amacıyla fuksin testi yapılmıştır. Fuksin testi için, 400 bar basınç altında 4 saat süre ile bir boya çözeltisinin bulunduğu basınç kabında parçalar işleme tabi tutulmuştur. Bir süre sonra parçalar cihazdan çıkarılarak, su ile yıkama işleminin ardından kırma işlemi gerçekleştirilmiştir. Kırılan yüzeylerde boya nüfuzunun olup olmadığı incelenmiştir. Tane boyut dağılımının tespiti amacıyla Master Sizer 2000 marka cihaz kullanılarak, 0,02$2000 \mu \mathrm{m}$ tane büyüklükleri arasında ölçüm işlemleri gerçekleştirilmiştir. Numunelerin XRD (X-ışınları kırınımı) analizleri, Bruker marka D8 ADVANCE model XRD cihazı ile yapılmıştır. Numunelerin mikroyapısal karakterizasyonu ise SEM cihazı kullanılarak gerçekleştirilmiştir. Malzemelerdeki morfolojik ve elementel düzeydeki incelemeler, SEM cihazı ile bağlantılı çalışan EDS (Enerji dağılımlı xışınları analizi) analizi cihazı kullanılarak yapılmıştır.

\section{BULGULAR VE TARTIŞMA (RESULTS AND DISCUSSION)}

Tane boyut dağılımı; izolatör hammaddelerinin, sır hammaddelerinin ve bunların süspansiyon halindeki karışımları açısından oldukça önemlidir. Tane büyüklüğü, katı faz reaksiyonlarında etkili olduğu bilinmekte ayrica ince taneli olunca daha büyük yüzey alanı ile reaksiyon daha hizlı olmakta ve buna benzer katı sıvı reaksiyonlarında da etkisi vardır. Tane büyüklüğü aynı zamanda yoğunluğu, mekanik mukavemeti ve poroziteyi etkilemektedir [3]. Katkı oranına bağlı olarak tane boyut dağılım değerleri Tablo 2' de verilmiştir. Katkı oranı arttıkça tane boyutu dağılımı düşmekte fakat $\% \quad 0,3$ oranında katılan borik asitten sonra tane boyut dağılımı tekrar yükselmektedir. Yapıda düşük tane boyutu istenildiğinden $\%$ 0,3 oranındaki katkı oranı idealdir. Katkı oranının artması ile birlikte tane boyutunda artışın olduğu gözlemlenmiştir.

Tablo 2. Borik asit katkılı ve masse tane boyut dağılım değerleri

(Particle size distrubition values of masse reinforced with boric acid)

\begin{tabular}{|c|c|c|c|c|}
\hline & $\begin{array}{c}\text { \% 0,1 BorikAsit } \\
\text { Katk1l1 Masse }(\mu \mathrm{m})\end{array}$ & $\begin{array}{c}\% 0,3 \text { Borik Asit } \\
\text { Katk1l1Masse }(\mu \mathrm{m})\end{array}$ & $\begin{array}{c}\text { \% 1 Borik Asit } \\
\text { Katk11 Masse }(\mu \mathrm{m})\end{array}$ & $\begin{array}{c}\text { İşletme } \\
\text { Masse }\end{array}$ \\
\hline $\mathrm{d}(0,5)$ & 10,854 & 9,434 & 9,804 & 9,841 \\
\hline $\mathrm{d}(0,9)$ & 44,377 & 37,553 & 39,380 & 38,932 \\
\hline
\end{tabular}




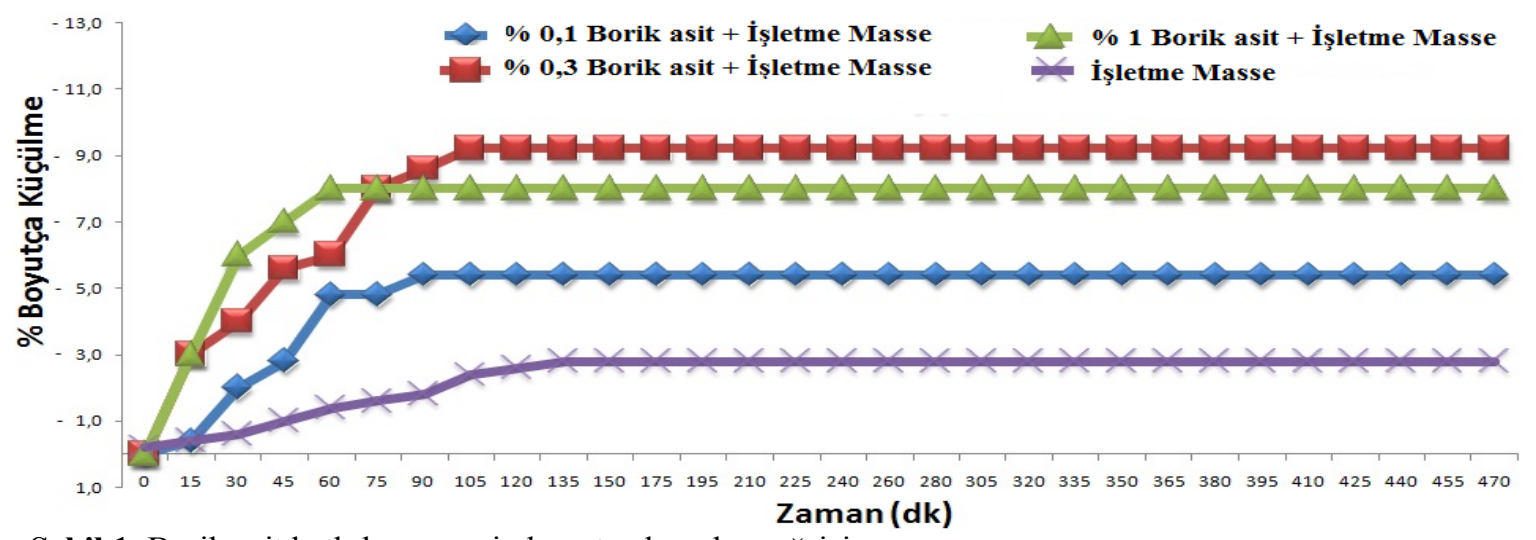

Şekil 1. Borik asit katkılı massenin boyutça küçülme eğrisi (Size reduction curve of masse reinforced with boric acid)

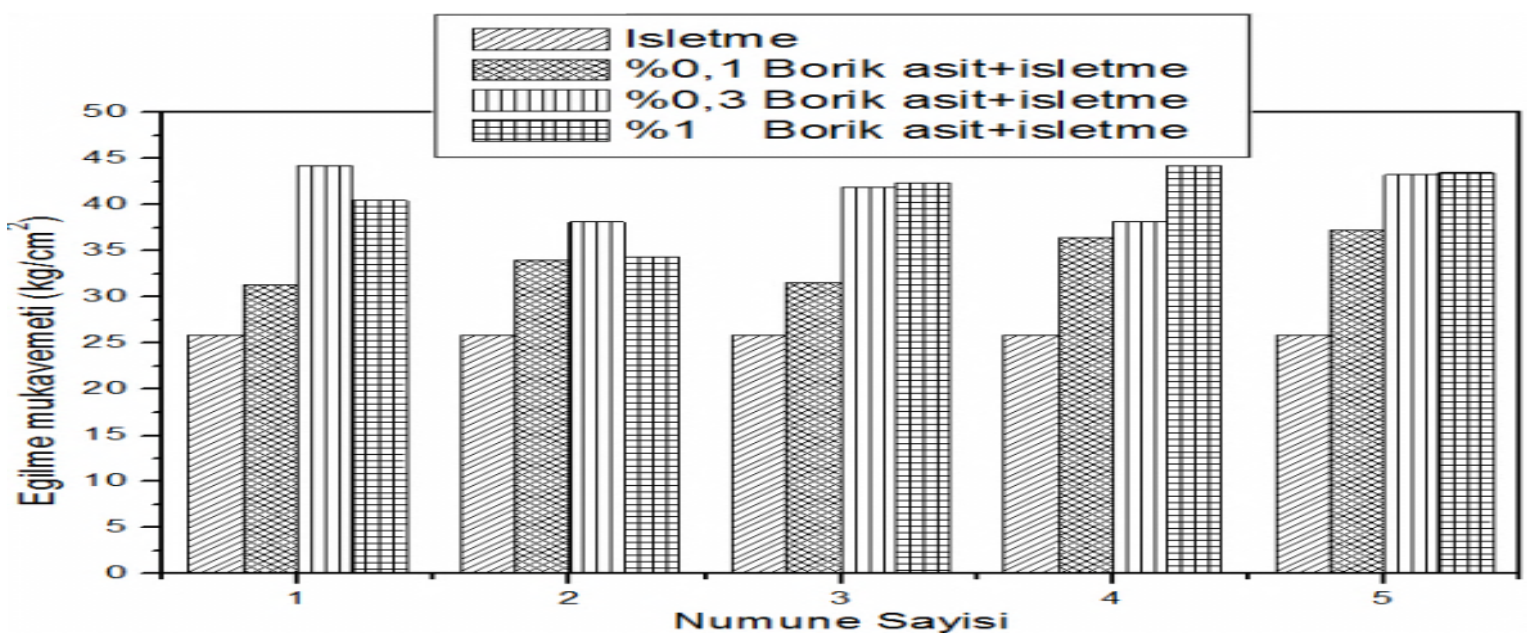

Şekil 2. Kuru mukavemet grafikleri (Dry strength graphs)

Şekil 1'de, yapılan katkı oranına bağlı olarak boyutça kuru küçülme grafikleri verilmiştir. Şekilde görüldüğü gibi katkı oranı arttıkça kuru küçülme oranında artma gözlemlenmiştir. \% 0,1 borik asit katkılı numune 90 dakikada, \% 0,3 borik asit katkılı numune 105 dakikada, \% 1 borik asit katkılı numune 60 dakikada, işletme masse ise 135 dakikada küçülme değerleri sabitlenmiştir. Üretilen ürünlerin mukavemet değerinin belirlenmesi amaciyla yapilan test sonucunda elde edilen kuru mukavemet sonuçları Şekil 2' de gösterilmiştir. İşletme masseye yapılan borik asit katkı miktarı arttıkça mukavemetin \% 0,3'e kadar arttığı, \% 0,3'den sonra mukavemetin azalma eğiliminde olduğu tespit edilmiştir. Ancak bu azalma işletme massesi baz alındığında ciddi bir artışın sonunda gelen bir azalmadır.

Sonrasındaki pişme mukavemet sonuçları ise Şekil 3'te gösterilmiştir. İşletme masseye yapılan katkı miktarı arttıkça mukavemet değerinin de arttığı görülmüştür. $\mathrm{Bu}$ artışın sebebini, pişme sonrası massenin içerisindeki alümina ve kuvarsın bir bağ

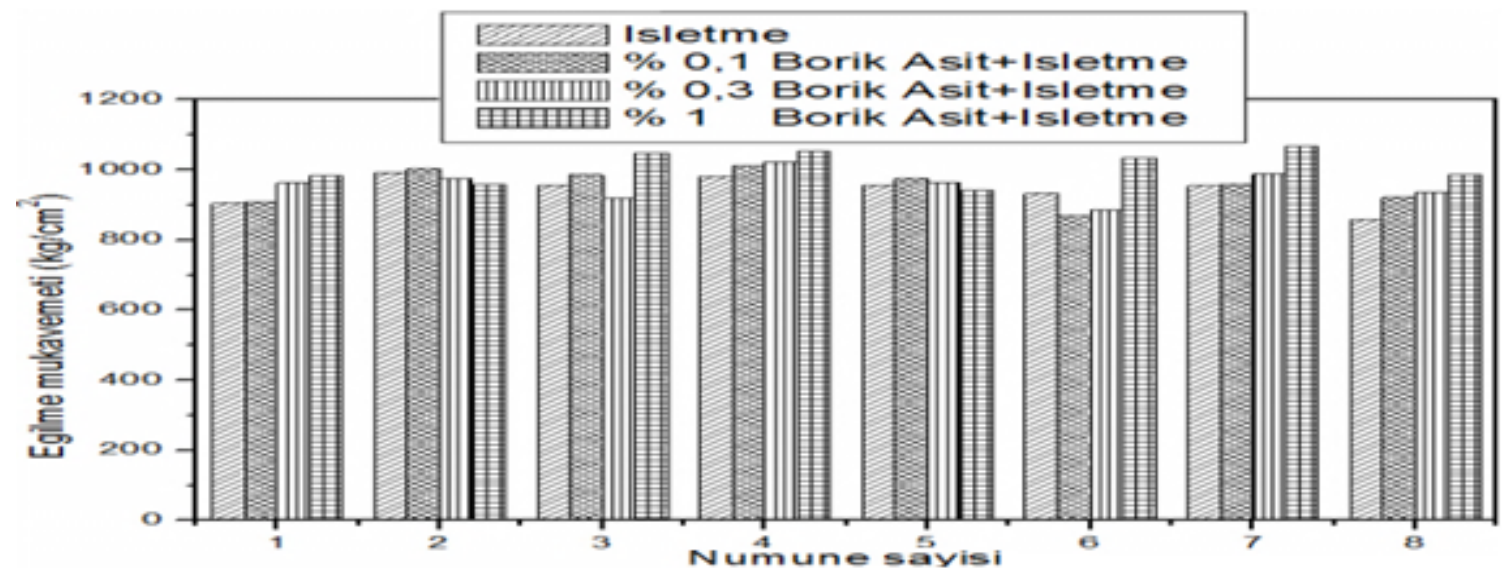

Şekil 3. Pişme mukavemet grafikleri (Burned strength graphs) 
oluşturarak müllite dönüşmesi ve müllitin mukavemete etki etmesiyle açıklanabilir. Bu durum göstermektedir ki borik asit gibi sinterleme sıcaklığında düşüşe neden olan katkı maddeleri bu düşüşle birlikte sinterlemenin etkisini arttırmakta ve mukavemeti olumlu yönde etkileyici bir rol oynamaktadır [6, 9]. Fuksin çözeltisinden çıkarılan numuneler çekiçle kırılarak bünyenin içerisine morumsu boyanın girip girmediğine bakılmıştır (Şekil 4). $\mathrm{Bu}$ teste tabi tutulan numunelerin hiçbirinde sıvının bünyeye girdiği görülmemiştir. Dolayısıyla gözenekliliğin veya herhangi bir mikro çatlağın olmadığı söylenebilir. Kurutma ve pişirme işlemleri sırasında meydana gelebilecek gözeneklilik ve mikro çatlakların oluşumu oldukça önemlidir. Borik asit katkılı numunelerde de herhangi bir nüfuziyet olmamıştır. Pişmiş numunelerin mukavemet sonuçlarının ortalaması baz alındığında mukavemet oranının artmakta olduğu, işletme masse ile \% 1 katkı oranı karşılaştırıldığında mukavemet değerinde \% 7'lik bir artışın olduğu dikkat çekmektedir. Mikroklin ve sanidin fazlarının K-feldspatın formları olduğu bilinmektedir.

Şekil 5'deki XRD analizinde mikroklin ve sanidin fazlarının görülmesinin sebebi bu şekilde ilişkilendirilebilir. Şekil 6'daki XRD analizinde ise kuvars, müllit ve potasyum bor silikat fazlarının olduğu tespit edilmiştir. Bu fazlardan potasyum bor silikatın reçetedeki K-feldspat'ın ve borik asit katkısıyla bir bağ oluşturarak bünyede oluştuğu şeklinde açıklanabilir. Faz değişimlerinin temelini teşkil eden sıcaklık ilişkisi ise müllite ve diğer fazlara dönüşüm sırasında oluşan yeni fazları belirlemektedir.

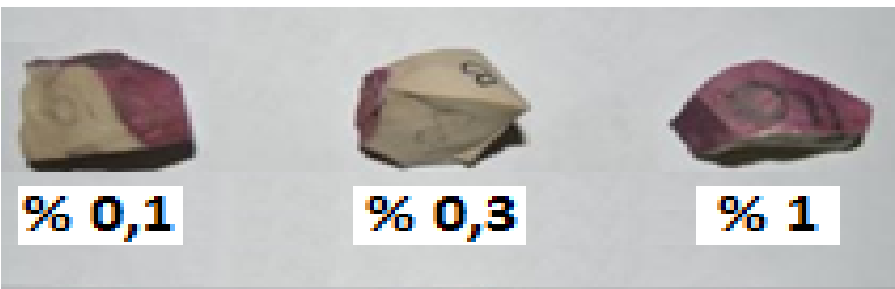

Şekil 4. Fuksin deneyi sonrası numuneler (Samples after fuksin experiment)

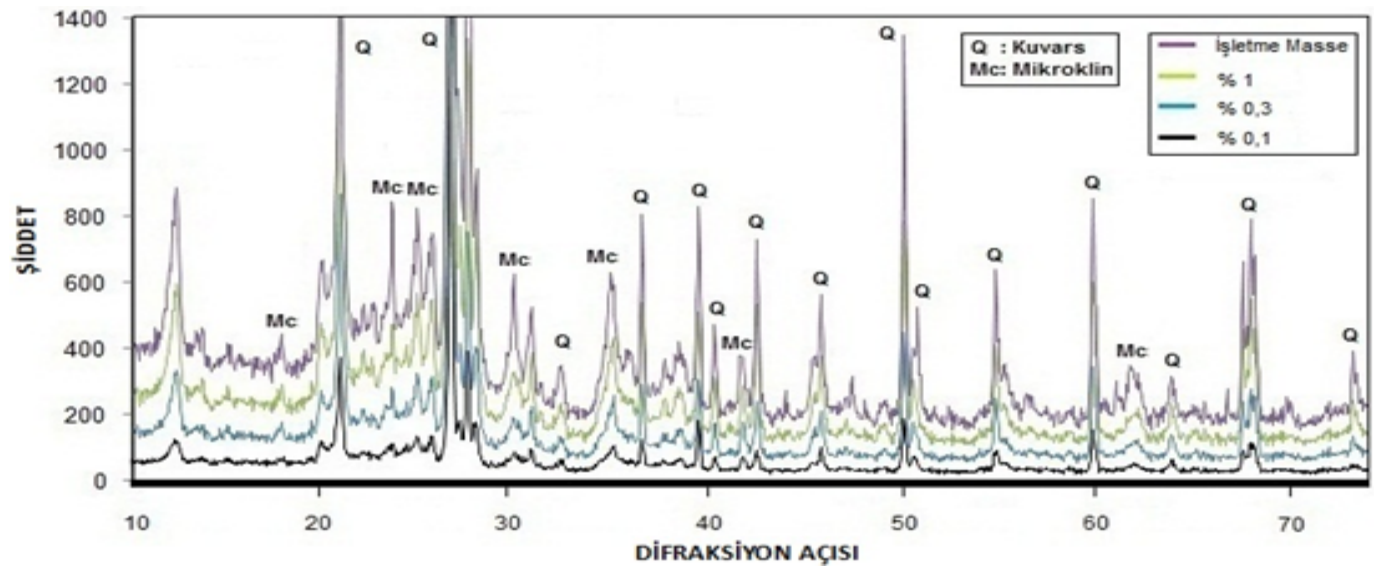

Şekil 5. \% 0,1, \% 0,3 ve \% 1 borik asit katkılı masse ve işletme massenin kuru XRD grafikleri (Dry XRD pattern of operation masse and masse reinforced with boric acid $0.1,0.3$ and $1 \mathrm{vol} \%$ )

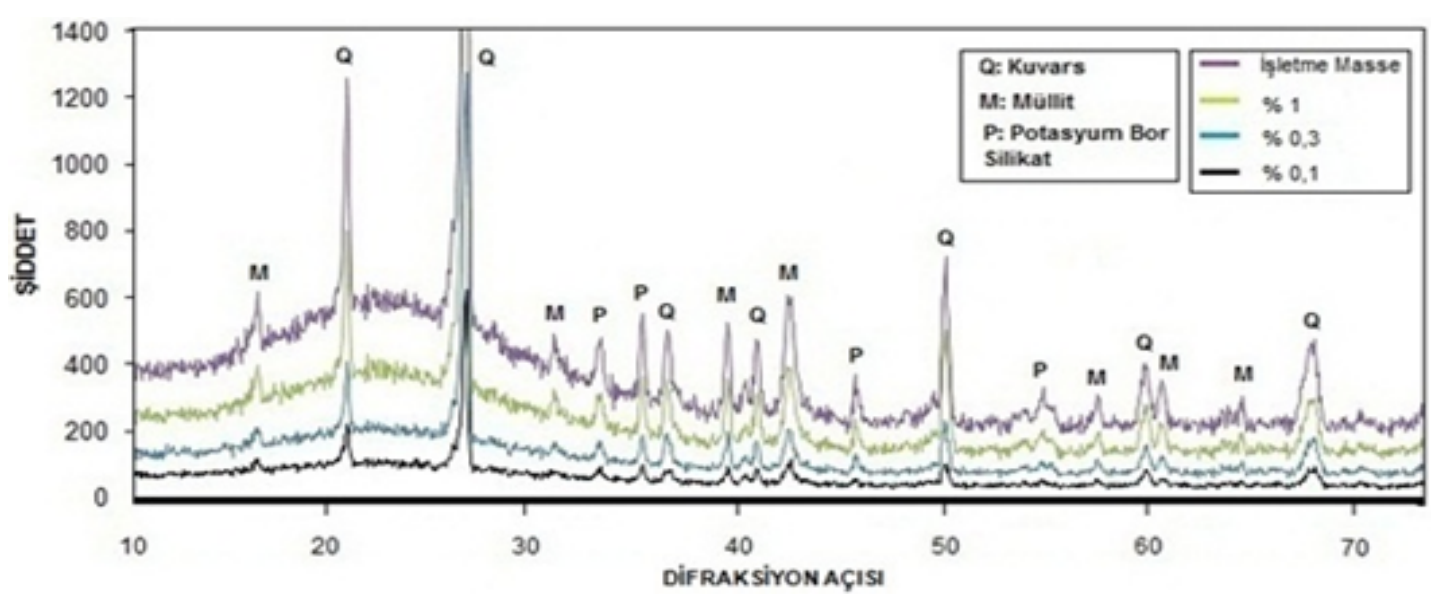

Şekil 6. \% 0,1, \% 0,3 ve \% 1 borik asit katkılı masse ve işletme massenin pişmiş XRD grafikleri (Burned XRD pattern of operation masse and masse reinforced with boric acid 0.1, 0.3 and 1 vol\%) 
Sıcaklık artışına bağlı olarak oluşan denge fazlarını etkileyen borik asit ilavesinin normal pişme şartlarını düşürdüğü tespit edilmiştir. Şekil 7' de kuru numunelerin kırık yüzeylerinin SEM görüntüleri verilmiştir. Şekil 7' deki işletme massesine yapılan, $\% 0,1, \% 0,3$ ve \% 1 borik asit katk1lı numunelerin kırık yüzey SEM görüntüleri incelendiğinde, kurularda beklenilen genel bulk numune ayrilma yüzeyi tavrı belirgin olarak gözükmektedir. Kopma tavrı olarak parçacıkların ham yoğunluktaki genel ayrılma karakteristiği sergilediği gözlemlenirken, SEM görüntülerinden anlaşıldığı üzere bölgesel olarak sinterleme öncesi tam birleşmenin gerçekleşmediği ya da kırılma sırasında ham mukavemetin yetersizliğinden dolayı ayrılan yüzeylerinde olduğu gözlemlenmiştir. Bu genel bir tavir olmamakla birlikte sinterlenmenin ileri safhalarında bu tür problemlerin ortadan kalkması beklenilir. Aynı numunelere ait $1255^{\circ} \mathrm{C}$ 'de 25 saat (13 saat pişme, 12 saat soğuma) sinterlenmiş
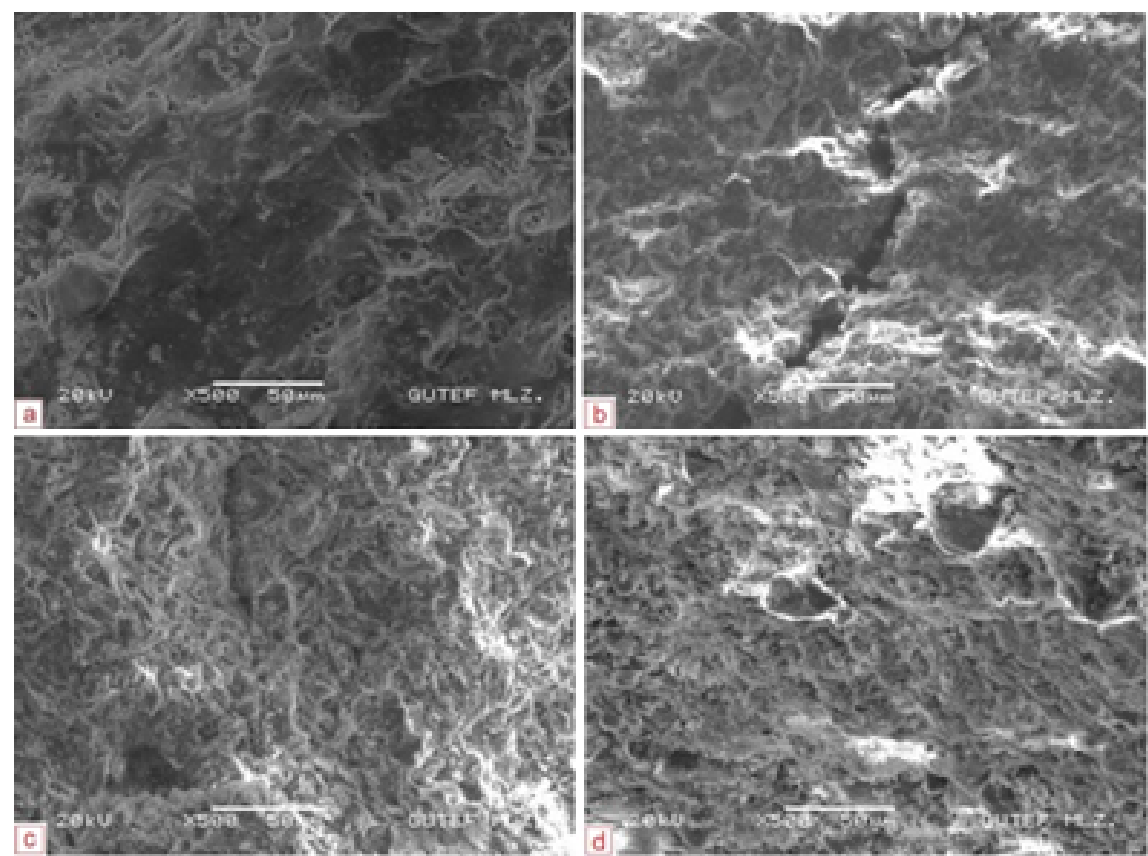

Şekil 7. Kuru numunelerin kırık yüzey SEM görüntüleri; a) İşletme masse b) \% 0,1 borik asit katkılı masse c) $\% 0,3$ borik asit katkılı masse d) \% 1 borik asit katk1lı masse (Fracture surface SEM images of dry samples; a) Operation masse, b) masse reinforced with boric acid $0.1 \mathrm{vol} \%$, c) $0.3 \mathrm{vol} \%$, d) $0.1 \mathrm{vol} \%$ )
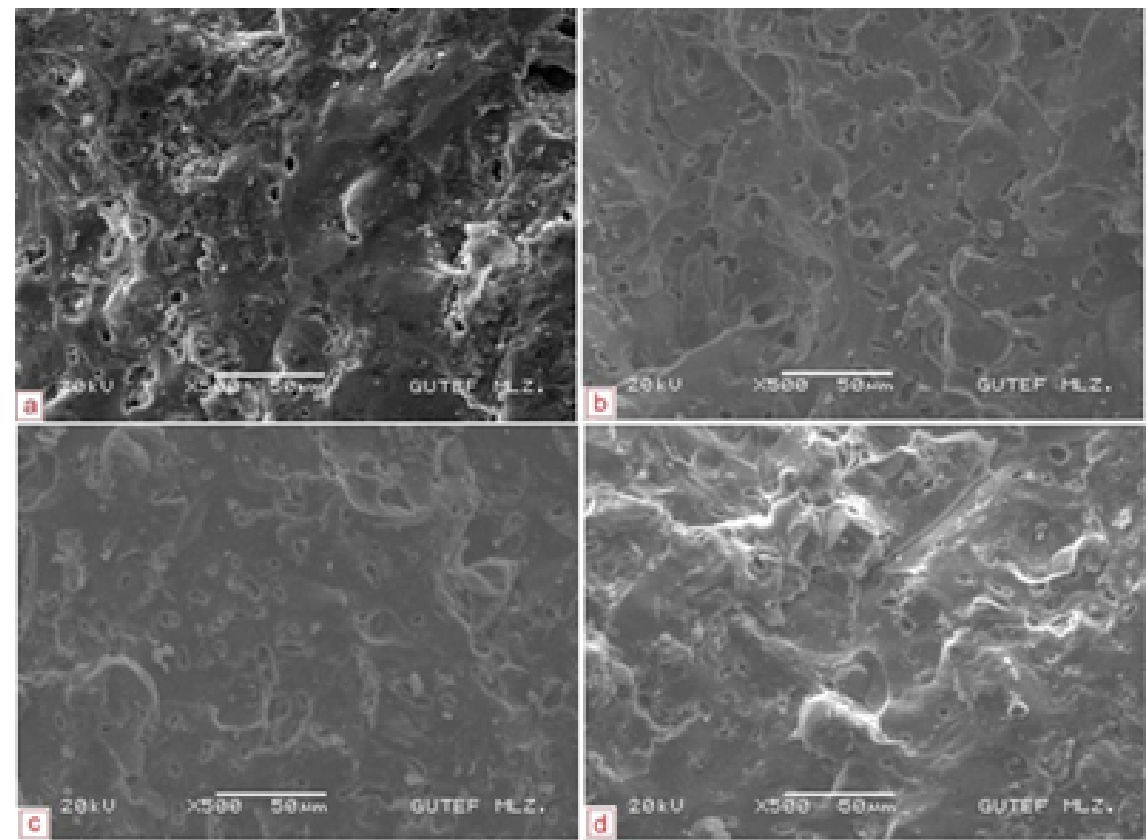

Şekil 8. Pişmiş numunelerin kırık yüzey SEM görüntüleri; a) İşletme masse, b) \% 0,1 borik asit katkılı masse, c) \% 0,3 borik asit katkılı masse, d) \% 1 borik asit katkılı masse (Fracture surface SEM images of burned samples; a) Operation masse, b) masse reinforced with boric acid $0.1 \mathrm{vol} \%$, c) $0.3 \mathrm{vol} \%$, d) $0.1 \mathrm{vol} \%$ ) 
numunelerin SEM görüntüleri incelendiğinde ise, seramiklerde beklenilen kırılma şeklinde meydana gelen ayrılmanın belirgin olduğu gözlemlenmiştir (Şekil 8). Şekil 8 incelendiğinde yapıda oluşan $\mathrm{SiO}_{2}$ birincil ve ikincil müllit fazlarının oluşumunu tamamladığı gözlemlenmiştir. Ayrıca gözenek morfolojisi incelendiğinde tamamen izole gözeneklerin oluşumu sinterlemenin tamamlandığını göstermektedir (Şekil 9).

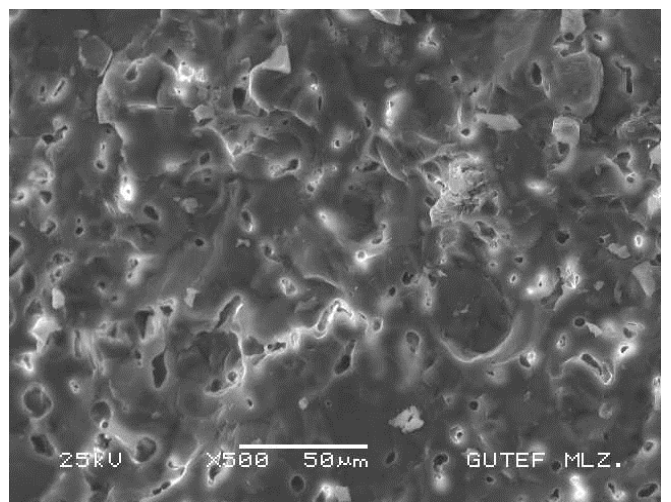

Şekil 9. \% 0,1 borik asit katkılı pişmiş massenin kırık yüzey SEM görüntüsü (Fracture surface SEM images of burned masse reinforced with boric acid $0.1 \mathrm{vol} \%$ )
Şekil 10 daki SEM görüntüsünde, oluşan müllit (M) fazı matrisin tamamını kaplamıştır. Matris içerisinde keskin köşeli, belirgin fazların $\mathrm{SiO}_{2}$ (S) olduğu, parçacık şeklinde müllit içerisinde dağılmış olarak görülen daha küçük parçacıkların $\mathrm{Al}_{2} \mathrm{O}_{3}$ (A) olduğu tespit edilmiştir. EDS incelemeleri $\mathrm{B}, \mathrm{Si}, \mathrm{Al}, \mathrm{Na}, \mathrm{K}$ elementleri seçilerek yapılmıştır. Burada $\mathrm{Si}$, ana matris elementidir (Şekil 11).

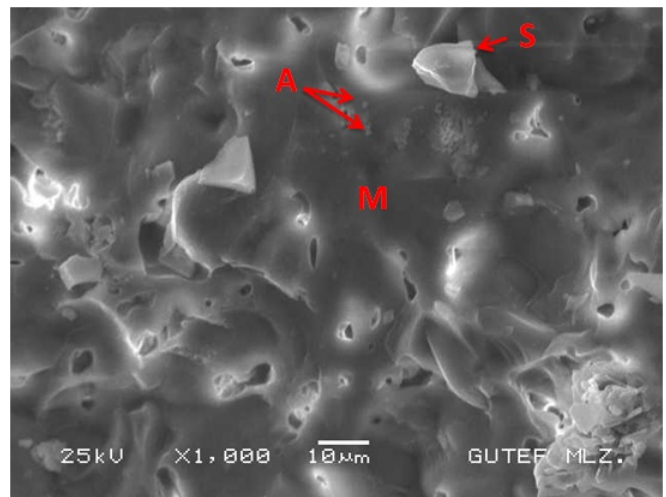

Şekil 10. \% 0,1 borik asit katkılı pişmiş massenin kırık yüzey SEM görüntüsü (Fracture surface SEM images of burned masse reinforced with boric acid $0.1 \mathrm{vol} \%$ )

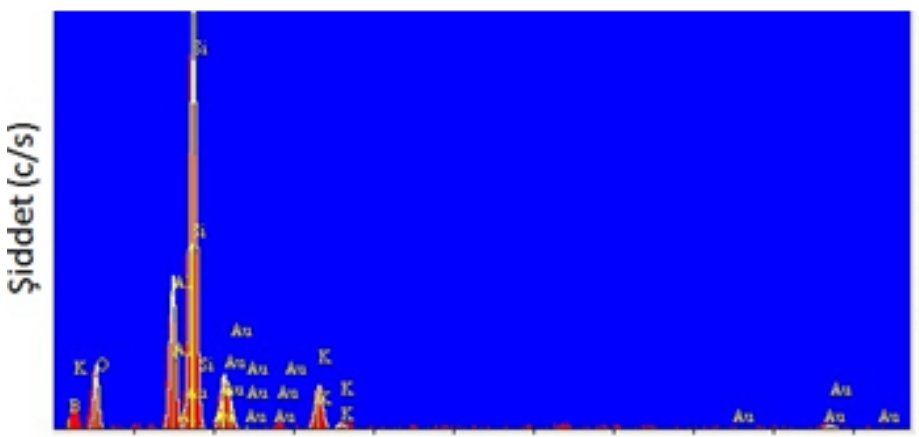

Enerji (keV)

Şekil 11. \% 0,1 katkılı pişmiş massenin SEM görüntüsündeki genel EDS analizi (The general EDS analysis in SEM image of burned masse reinforced with boric acid $0.1 \mathrm{vol} \%$ )
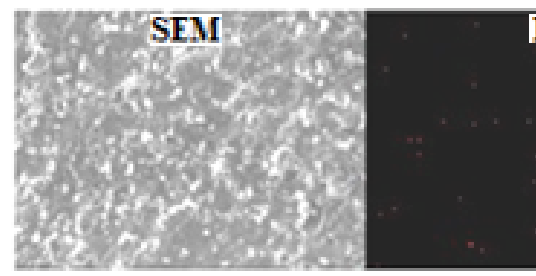

B
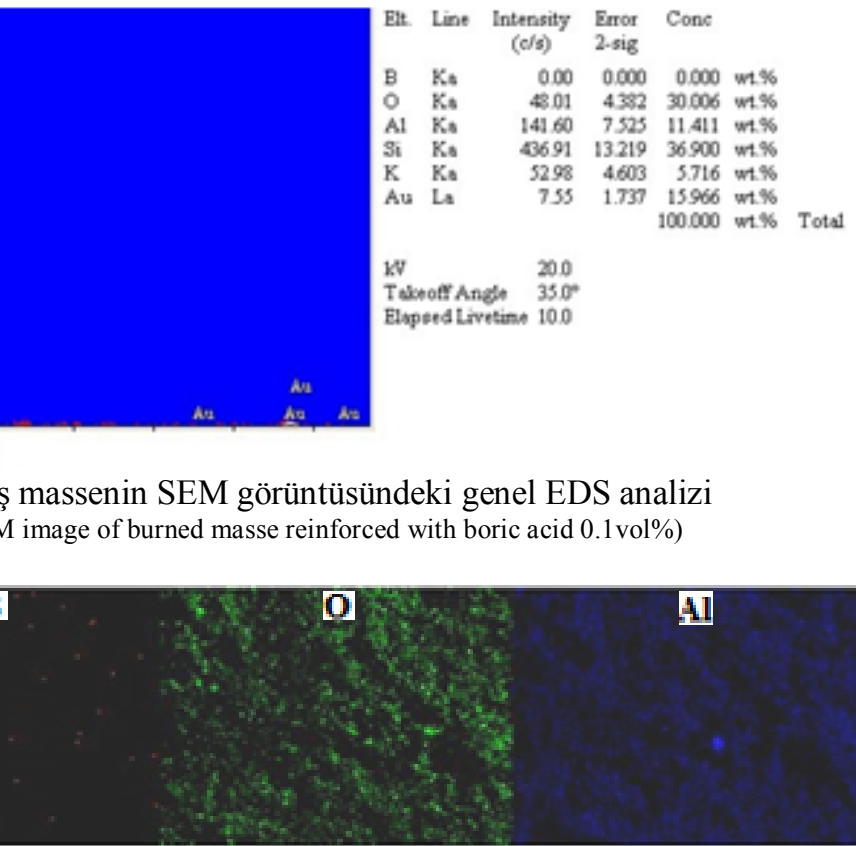

(c/s) 2 -sig

100,000 wt. $\%$ Total

20.0
$350^{\circ}$

Appes Livetiano 10.0

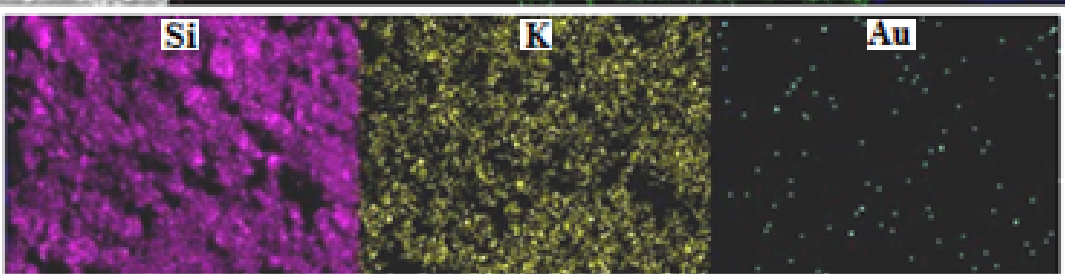

Şekil 12.\% 0,1 borik asit katkılı pişmiş massenin element dağılım haritası

(Element distribution map of burned masse reinforced with boric acid $0.1 \mathrm{vol} \%$ ) 
EDS analiz sonucunda her ne kadar B elementinin \% skalada herhangi bir değeri olmasa da, Şekil 11 incelendiğinde B'a ait pikler görülmektedir. EDS analizinde genel problem olan atom numarası küçük elementlere ait pik şiddetlerinin düşüklüğü buradaki borun tespitindeki güçlüğün temel sebebidir. Aynı zamanda ilave edilen miktarın azlığı da buna etki etmektedir. Yapılan tüm noktasal ve bölgesel EDS analizleri sonuçlarında borun varlığı net bir şekilde tespit edilememiştir. Borun tespiti amacı ile yapılan \% 0,1 borik asit katkılı pişmiş masseden alınan element dağılım haritasında borun homojen bir şekilde yapı içerisinde dağıldığı tespit edilmiştir (Şekil 12). Bu oranın \% 1 borik asit katkılı numunelerde daha belirgin olduğu söylenebilir.

\section{SONUÇLAR (CONCLUSIONS)}

Elektro porselen massesine borik asit katkısı yapılarak geliştirilen malzeme özellikleri bakımından, deneysel çalışmaların sonucu aşağıda özetlenmiştir;

Yapıda düşük tane boyutu istenildiğinden, \% $\quad 0,3$ oranındaki katk1 oranının ideal olduğu tespit edilmiştir. Kuru küçülme oranında katkı yapıldıkça artış belirlenmiştir. Küçülmesi erken sabitlenen numune \% 1 borik asit katkılı olarak tespit edilmiştir. Katk1 yapılan numunelere fuksin testi uygulanarak, numunelerin gözeneksiz bir yap1 sergilediği belirlenmiştir. Kuru mukavemet açısından, masseye yapılan katkı miktarı arttıkça mukavemetin \% 0,3'e kadar arttığı belirlenmiştir.

Pişme mukavemeti ise, işletme masseye yapılan katkı miktarı ile mukavemet değerindeki artışla sonuçlanmıştır. İlave edilen borik asitin yapıda homojen bir şekilde dağıldığı, ayrıca bu durumun sinterleme tavrı açısından olumlu yöndeki bir etkisi olarak belirlenmiştir.

\section{KAYNAKLAR (REFERENCES)}

1. Barsoum, M. W., "Fundementals of Ceramics", Series in Materials Science and Engineering, Department of Materials Engineering, Drexel University, IOP Publising LTD, 2003, 2-12.

2. Aydın İpekçi, C., Aköz, F., "Seramik ve seramiklerin şekillendirilmesinde kullanılan kalıp alçısının özellikleri” Mühendislik ve Fen Bilimleri Dergisi-Sigma, Cilt 28, 249-258, 2010.

3. Çetin, E., Özer, N.L., Çetin, M., "Porselen izolatörlerde izolasyon problemleri" Pamukkale Üniversitesi-Mühendislik Bilimleri Dergisi, Cilt 11, 287-292,2005

4. Özgen, S., Kale, H., Kolat S., "Porselen izolatörde proses parametrelerinin özelliklere etkisi” Uluslararası Seramik Kongresi, İstanbul Teknik Üniversitesi, İstanbul, 44, 1992.

5. Aydın, T., Kara A., "Borik asit ilavesinin elektro porselen bünyelerin sinterlenme davranışları üzerine etkisinin incelenmesi", Afyon Kocatepe Üniversitesi Fen Bilimleri Dergisi, Özel Say1: 53-60, 2012.

6. Cengiz, Ö., Kara A., "Tek pişirim duvar karosu bünyelerinde borik asit ilavesinin sinterleme davranışına etkileri”, Afyon Kocatepe Üniversitesi Fen Bilimleri Dergisi, Özel Sayı: 29-35, 2012.

7. Görhan, G., "Bor oksit ve borik asit katkısının kil tuğlası özelliklerine etkisi" Selçuk Üniversitesi Teknik-Online Dergi, Cilt 11, 96-109, 2012.

8. Mutlu, İ., Çevik İ., Öner C., ' Fren balatalarında boraks ve borik asit'in etkilerinin deneysel incelenmesi", I. Uluslar Arası Bor Sempozyumu, Dumlupınar Üniversitesi, Kütahya, 160-165, 2002.

9. Abalı, Y., Bayça, S. U., Yürük, H. K., Gümüş, R., "Vitrifiye kırıklarının seramikte tekrar kullanılabilirliğine borik asidin etkisi", Üniversite Öğrencileri IV. Çevre Sorunları Kongresi (ÇESKO 2009), Fatih Üniversitesi, İstanbul, 81, 2009. 
